\title{
AC 2009-664: HOW SHOULD ELECTRONICS TECHNOLOGY BE TAUGHT TODAY? A FRESH LOOK AT THE TOP DOWN APPROACH FOR ASSOCIATE DEGREE PROGRAMS
}

\section{Louis Frenzel, Electronic Design Magazine}

Louis E. Frenzel Jr.

Lou Frenzel is a Technology Editor for Electronic Design Magazine where he writes articles, columns, technology reports, and online material on the wireless, networking, and test/measurement sectors. He interviews executives and engineers, attends conferences, and researches those areas of electronics to determine the current state of the technology and reviews new products. Lou has been with the magazine for 7 years. Formerly he was professor and department head at Austin Community College where he taught electronics for 5 years. He still teaches at ACC as an Adjunct Professor. Lou has 25+ years experience in the electronics industry. He holds a bachelor's degree from the University of Houston and a master's degree from the University of Maryland. He is author of 19 books on computer and electronic subjects. He has worked with MATEC as a contractor for 5 years on several NSF grants and is the principal author of the Work-Ready Electronics series and participates in the Esyst project. 


\section{HOW SHOULD ELECTRONICS TECHNOLOGY BE TAUGHT TODAY? A FRESH LOOK AT THE TOP-DOWN APPROACH FOR AAS DEGREE PROGRAMS}

Introduction

Most two year AAS degree programs in electronic programs still teach a version of electronics more in keeping with the way things used to be rather than the way things are today. A mix of faculty resistance to change, bureaucracy and politics in the college administration, lagging views of accrediting bodies, lack of lab funding, and little or no industry input has contributed to the retention of a dated curriculum skewed from real industry needs. Change is always difficult so most colleges react to change later than they should rather take a proactive approach to continuous improvement Engineering and technology colleges realize that continuing rapid changes in electronic components, technologies, methods, equipment and jobs are the norm but find it difficult to keep courses and curriculum are in step. Yet, more than ever it is essential that academia match industry and the consumer in keeping up with the technology.

One way to update and improve the technician-level electronics curriculum is to adopt a systemsoriented rather than a component/circuit analysis approach that most schools still use. Thanks to high density integrated circuits, fewer and fewer discrete component circuits are in use today yet most two-year schools continue to teach the analysis and design of discrete component circuits that few technicians actually encounter today. The modern technician works with equipment, pre-assembled PC boards, modules, subassemblies and integrated circuits that create the systems and end-products. There is less need for detailed circuit analysis and design or troubleshooting to the component level. The modern technician works more at the block diagram/signal flow level rather than the schematic level in performing his or her normal tasks of troubleshooting, maintenance, repair, service, calibration, testing and measurement to standards.

One program addressing this change opportunity is the three year NSF eSyst project ${ }^{1}$ that is studying how to implement a systems approach in electronic technology programs. In its second year, the project is proposing how course content can be revised to deliver the knowledge and skills needed by an electronic technician today.

This paper gives an example of how a pilot course in basic Solid State Circuits and Devices has been taught using a modified top down approach to increase interest and student motivation as well as an attempt to improve retention. This pilot test was initiated to assess the difficulties, problems and issues that might be encountered by other instructors attempting to adopt the systems approach being proposed. Topics such as content, sequence, instructional materials, lab exercises, and textbooks are covered. 


\section{The Top-Down Approach}

As part of the eSyst project, the top-down approach ${ }^{2}$ to teaching electronics has been seriously studied and reconsidered. Most programs today still use a bottom up approach that begins with math and science, progresses to basic electrical theory and components, electronic circuits, embedded controllers, and eventually equipment and systems. This is still a logical progression but it does not address the problems that it creates such as student boredom, disinterest, difficulty, motivation and ultimately withdrawal. Students frequently drop out in the early courses simply because they cannot relate the need for the theory to the real world work and jobs and because of the extensive math and analysis. "Why am I learning this?" is a major factor in student retention. And many early required courses never answer the question. Perhaps a better approach is a top down "how it works" presentation of electronics starting with the applications, systems, equipment then eventually delving deeper into the circuits and the components. It is a more interesting approach and can be implemented to the degree needed in each school according to local industry requirements.

If it were possible to create a curriculum from scratch for today's technician, the top down approach would certainly be a major alternative. It starts with the application or equipment then digs deeper into the system to identify major components such as modules or PC boards. The circuits are then considered. Ultimately the individual components and electrical theories would be introduced.

As it turns out, the top down approach is too idealistic to actually work in contemporary college and university programs. For the eSyst grant, this approach was considered, analyzed, debated and ultimately discarded. There are several reasons for this. First, the student needs some basic theory as a background to understand even a high level view of an application. Second, such an approach is simply incompatible with the way current curricula and courses are structured today. The chances of a college adopting such a method is low if not impossible given the difficulty of revising any program or course because of administrative and state requirements, credit transfer arrangements and accreditation policies.

As a result, the grant committee decided to stay with the standard curricula so common to community college AAS degree electronic technology programs. The plan is to revise and update the individual courses to incorporate a more systems oriented view along with elements of a top-down approach that can be implemented within the course.

What is the Systems View?

In building a curriculum emphasizing the systems view we started with the available technician jobs and industry requirements. This involved reviewing available jobs requirements, discussing needs with industry employers, and seeking input from an industry advisory group. More and more employers are looking for technicians and want them to have a strong background in the fundamentals but also knowledge and skills such as how to work in teams, 
how to communicate better in writing and verbal presentation. Most industries support if not demand a more systems orientation to courses and content. Several key facts were confirmed:

- Most technicians do not do detailed circuit analysis or design.

- Technicians primarily do service and maintenance work, equipment installation and troubleshooting, and a considerable amount of test and measurement.

- There is less need to troubleshoot and repair to the component level. While this is still a needed skill in some fields it is a small percentage of the overall need. Most repair is board swapping, module replacement, and similar actions that restore operation faster.

Strangely, while most employers seem to agree with the systems approach, their hiring practices and particularly any technician hiring exams do not seem to indicate it. A close look at a half dozen company hiring exams reveals their highly dated nature. The older exams still test for fundamentals that today rarely matter. Some examples include troubleshooting a vacuum tube phase shift oscillator, biasing a bipolar transistor, and minimizing a very difficult Boolean equation. The grant committee members have heard many times from faculty that the reason the older less relevant material is still taught is so that graduates can pass the dated entry level hiring exams. This is serious problem which no one has addressed.

Message to industry: Your products and methods are typically up to date but please do revise your hiring exams to better test for your real needs rather than some older perceived need.

Since most courses today involve detailed circuit analysis and design, they are less relevant to the real needs of industry. Some component and circuit theory is indeed necessary but the degree to which those subjects are taught can be reduced while introducing a higher level view of electronics that is more interesting to students and to employers. ${ }^{3}$

A system view of electronics has the following characteristics.

- Focus on the INPUT-PROCESS-OUTPUT approach to electronic circuits and equipment.

- Increased emphasis on the characteristics of signals used as inputs and received as outputs.

- A black box approach to processing.

- Introduce circuit characteristics and specifications without actual circuit details.

- More emphasis on integrated circuits.

- Increased attention to the characteristics of interfaces.

- More analysis of equipment using block diagrams and signals flow. 
- Viewing most applications as they really are: embedded controllers surrounded by I/O and applications circuits and interfaces.

- Less detailed circuit analysis and design.

By using this approach, a considerable amount of previously taught material can be eliminated to make way for more of a higher level approach that stresses troubleshooting, testing and measuring.

Applying the Systems Approach to a Solid State Circuits Course

Virtually all AAS degree electronic technology programs include a basic Solid State course that may be called by that name or alternate names such as Semiconductor Devices and Circuits or Linear Circuits. The prerequisites of this course are typically the completion of courses in DC and AC electrical fundamentals. The subjects taught usually include:

- Introduction to semiconductor materials.

- Diodes, types and operation.

- Transistor types and operation.

- Transistor biasing.

- Power supply circuits (rectifiers, filters, etc.)

- Amplifiers, types and applications.

- Switching circuits, transistor and IC.

- Operational amplifiers

- Power supply regulators.

- Thyristors and basic circuits.

There are at least one half dozen textbooks that cover these subjects for use in this course. Most of this coverage is heavily component and circuit oriented. And since most instructors still "teach the text" the courses follow that dated orientation. There is little or no mention or coverage of larger pieces of equipment or systems using these components and circuits yet what most graduates will do is work on the equipment rather than dig down into the circuits. Most circuits are inside ICs anyway so there is less need today to know detailed circuit details or analysis or design methods. Technicians do not design and they rarely analyze circuits. But they do test them and troubleshoot them. The knowledge needed is clearly more at a higher level. The textbook issue is clearly one that needs to be addressed. 
The outline for the course remains essentially the same as given above. But the degree, breadth and depth of coverage of each topic are modified. ${ }^{4}$ And new systems examples are added. Here are the suggested revisions and the rationales for each:

- Reduce coverage of semiconductor theory. In reality, since virtually everything in electronics is semiconductor-based, the eSyst project recommends teaching semiconductor theory in the first entry level course, typically DC circuits or Circuit Analysis. More details can be provided in the Solid State course. It is useful to know about $\mathrm{P}$ and $\mathrm{N}$ type materials, covalent bonds and depletion regions but discussing energy levels is unnecessary. Be sure to mention compound semiconductors ( $\mathrm{GaAs}, \mathrm{SiGe}, \mathrm{InP}$, etc) which are very common today.

- Reduce coverage of bipolar junction transistors (BJTs). Over $90 \%$ of all transistors in use today are MOSFETs. Most ICs are made with MOSFETs. Bipolars are still widely used but not as much as in the past. They are actually a minority device. They must be covered, of course, but less detail is needed today.

- Increase coverage of MOSFETs. In fact, there is a good argument to be made for teaching MOSFETs before BJTs. Most courses do not give as much coverage to what is the base of virtually all electronic circuits today.

- Eliminate detailed analysis of BJT circuits. Few if any technicians or even engineers ever have to know what $r_{\mathrm{e}}$ ' is or how to bias and analyze a BJT circuit. Some elementary biasing concepts do indeed need to be taught (e.g. bias conditions for linear operation) but not to the degree it is still covered in many books and schools today.

- Increase coverage of MOSFET circuits, but it is not necessary to discussed detailed biasing methods. Most texts and courses completely omit discussion of current sources and sinks, current mirrors and use of MOSFETs as resistors and how these are used to bias linear circuits. Again basic concepts are necessary but few details are needed and certainly not at the engineering design level.

- Increase coverage of ICs. Most circuits are ICs so it is recommended that types of IC amplifiers and other relevant linear and switching circuits be taught. Emphasize amplifier specifications (gain, input and output impedances, bandwidth, power capability, etc.) and applications. Include common tests and measurements (gain, noise, distortion, frequency response, rise time, etc.)

- Include class D and other switching amplifiers which are a major category today but rarely covered in modern Solid State courses. 
- Include increased coverage of power supplies specifically switching regulators which are the predominant type today. Emphasize the green movement toward less power consumption and greater efficiency. Batteries and battery charging should also be covered. Include coverage of power supplies as a system. Most products have a hierarchy of power supply circuits including rectifiers, filters, a bus architecture, multiple regulators and types (switching, LDO, etc), DC-DC converters, and power management circuits. All are relevant today.

- Include phase-locked loops (PLL) as this basic circuit is part of many other circuits and systems. Name just one modern electronic product that does not include a PLL.

Implementing a Solid State Course

The above suggestions were implemented in the Solid State Devices course CETT 1429 at Austin Community College during the 2007 and 2008 time period. The State of Texas has specific course standards (Workforce Education Course Manual) but they are flexible and define only minimal requirements making it possible to include the desired changes. The textbook used was Introductory Electronic Devices and Circuits, $7^{\text {th }}$ edition, Pearson/Prentice Hall by Robert T. Paynter.

The textbook is professionally written but it takes the traditional circuit analysis approach with a heavy BJT bias. Furthermore, it does not adequately cover (if at all) some of the more advanced topics suggested above. MOSFETs are seriously neglected as are other topics especially power supply related. Of the 21 chapters in the book about one third of them were not used in this course and in the other chapters multiple sections were omitted.

A survey of competitive textbooks indicates that most of them cover the same material, in the same way, but also ignore or only minimally cover many of the newer topics. Some are more up to date than others. None cover electronics at the systems level or provide details on testing, measuring and troubleshooting to the degree appropriate to jobs today. None have high level systems examples.

To overcome the limitations, the textbook was supplemented with online tutorials that cover topics missing or inadequately covered. These tutorials were developed under an NSF-ATE grant and are available on line from the Maricopa Advanced Technology Education Center (MATEC) in Phoenix. The tutorials are referred to as Modules and can be accessed at www.work-readyelectronics.org. The modules used in the Solid State course were:

- Systems View of Electronics

- MOSFETs

- Switching Amplifiers 
- Switching Power Supplies

- Contemporary Power Supplies

- Phase-Locked Loops

- Troubleshooting

Students worked on the modules in class but could also complete them online at home if desired. The modules have exams to test for understanding and application.

Other course supplements included selected web references as well as relevant magazine articles used for handouts.

Systems Examples

An attempt was made to show more systems examples as part of the lectures. The systems illustrate how the various circuits are used putting them into better perspective for the student. Some the systems presented in block diagram signal flow format were:

- Stereo amplifiers.

- CD player

- $\quad$ MP3 player or iPod

- Public address/music sound system

- Advanced power supplies (PC and cell phone).

In most cases, actual physical units were demonstrated.

\section{Laboratory}

Unfortunately there are few commercial laboratory trainers or hands-on learning systems that teach electronic fundamentals at the systems level. Some schools build their own systems relevant to local needs, but most community colleges have only limited traditional test equipment (DMM, oscilloscope, function generator, power supplies, breadboards, etc.) more suited to a circuit analysis approach. In this pilot course, some of the typical traditional lab experiments were used as in previous courses such as experiments with diodes, BJTs, MOSFETs, and op amps. New experiments emphasizing the use of more ICs and extended op amp applications were developed and included. Testing and measuring methods were stressed.

One important observation is that modern labs would benefit by having prewired circuits to test, measure and troubleshoot. This not only saves lab time but also provides a student experience closer to the real world. 


\section{Conclusion}

After teaching the Solid State course in the older more traditional manner, it was an unusual experience to teach it in the new format. There was some trepidation about eliminating material previously considered so essential. Introducing the new material necessitated the creation of new lecture notes, presentations, lab experiments and demonstrations. This required considerable extra work but made teaching the course interesting again. The MATEC WRE online modules were a great help in teaching the new material.

One of the most frustrating parts of teaching the course in the new way was the lack of a textbook that included the more up to date material along with systems examples. Considerable time was spent in analyzing which textbook sections to include and omit. No current publisher offers a suitable book. This is a real opportunity for some author and publisher.

Another frustration was the lack of more system-oriented lab equipment. Current electronic products were used in demonstrations but are not really suitable for individual student work. It is hoped that lab equipment manufacturers address the opportunity to create low cost pre-wired system-like trainers that will give students a more hands-on real world experience.

As for the students, there was a significant boost in interest because of the applications and systems examples. Less mathematical analysis and design resulted in fewer drop outs and overall higher average grades over previously taught traditional sections. Many agree that a dated and out-of-touch curriculum may be partially to blame for the significant decline in electronic technology enrollments. ${ }^{5,6}$ With a more relevant curriculum there is more hope for attracting new students while also increasing the retention rates of existing students.

In the future, the eSyst grant team will conduct formal student evaluations to determine the true value of the program. Yet, these test courses revealed that improvements can yield benefits to students and to industry.

Bibliography

1. National Science Foundation, Advanced Technology Education, Division of Undergraduate Education, grant \#0702753, A Systems View of Electronics for 2010 (ESYST).

2. J. Robertson et al, "The Technology World is Changing Rapidly, Can Higher Education Match the Pace?", Proceedings ASEE Annual Conference, Pittsburg, 2008, \#1021.

3. J Robertson et al, "Perspectives on a Freshman Treatment of Electronic Systems", Proceedings ASEE Annual Conference, Pittsburg, 2008, \#1508. 
4. Frenzel, Louis. E., Jr., Are We Teaching the Right Subjects in AAS degree Electronic Technology Programs? The Technology Interface Journal, Spring, 2006.

5. Frenzel, Louis E., Jr., "The Disappearing Associate Degree Program in Electronics Technology”, 2003 Proceedings ASEE Annual Conference, Nashville, 2003, \#287.

6. G. Mullett \& A. Smith, “Are today's Engineering Technology programs doomed to extinction or is their mission changing?” Proc ASEE Annual Conference, Honolulu, June 2007, \# 2348. 